\title{
Changes in initiation of adjuvant endocrine therapy for breast cancer after state health reform
}

\author{
Kirsten Y. Eom ${ }^{*}$, G. J. van Londen², Jie Li ${ }^{1}$, Bassam Dahman, Cathy Bradley ${ }^{4}$ and Lindsay M. Sabik
}

\begin{abstract}
Background: Socioeconomic differences in receipt of adjuvant treatment contribute to persistent disparities in breast cancer (BCA) outcomes, including survival. Adjuvant endocrine therapy (AET) substantially reduces recurrence risk and is recommended by clinical guidelines for nearly all women with hormone receptor-positive nonmetastatic BCA. However, AET use among uninsured or underinsured populations has been understudied. The health reform implemented by the US state of Massachusetts in 2006 expanded health insurance coverage and increased the scope of benefits for many with coverage. This study examines changes in the initiation of AET among BCA patients in Massachusetts after the health reform.

Methods: We used Massachusetts Cancer Registry data from 2004 to 2013 for a sample of estrogen receptor (ER)positive BCA surgical patients aged 20-64 years. We estimated multivariable regression models to assess differential changes in the likelihood initiating AET after Massachusetts health reform by area-level income, comparing women from lower- and higher-income ZIP codes in Massachusetts.

Results: There was a 5-percentage point ( $p$-value $<0.001)$ relative increase in the likelihood of initiating AET among BCA patients aged 20-64 years in low-income areas, compared to higher-income areas, after the reform. The increase was more pronounced among younger patients aged 20-49 years (7.1-percentage point increase).

Conclusions: The expansion of health insurance in Massachusetts was associated with a significant relative increase in the likelihood of AET initiation among women in low-income areas compared with those in high-income areas. Our results suggest that expansions of health insurance coverage and improved access to care can increase the number of eligible patients initiating AET and may ameliorate socioeconomic disparities in BCA outcomes.
\end{abstract}

Keywords: Breast cancer, Adjuvant endocrine therapy, Massachusetts health reform, Health insurance, Cancer registry

\section{Background}

Breast cancer (BCA) is the second most common cancer and the second leading cause of cancer death among women in the US [1]. This is also the case in the state of Massachusetts, where about $30 \%$ of new cancer cases

\footnotetext{
* Correspondence: kirsten.eom@pitt.edu

'Department of Health Policy and Management, University of Pittsburgh, 130 De Soto St, A663, Pittsburgh, PA 15261, USA

Full list of author information is available at the end of the article
}

and $13 \%$ of cancer deaths among women from 2011 to 2015 were due to BCA [2, 3]. However, due in large part to advances in adjuvant therapies, overall BCA mortality rates have steadily declined since the 1970s, and relative 5 -year and 15-year survival rates among BCA patients were estimated to be 90 and $80 \%$, respectively in 2018 $[1,4,5]$. While mortality has declined overall, gains have been greatest in affluent areas and have lagged for

(c) The Author(s). 2021 Open Access This article is licensed under a Creative Commons Attribution 4.0 International License, which permits use, sharing, adaptation, distribution and reproduction in any medium or format, as long as you give appropriate credit to the original author(s) and the source, provide a link to the Creative Commons licence, and indicate if changes were made. The images or other third party material in this article are included in the article's Creative Commons licence, unless indicated otherwise in a credit line to the material. If material is not included in the article's Creative Commons licence and your intended use is not permitted by statutory regulation or exceeds the permitted use, you will need to obtain permission directly from the copyright holder. To view a copy of this licence, visit http://creativecommons.org/licenses/by/4.0/ The Creative Commons Public Domain Dedication waiver (http://creativecommons.org/publicdomain/zero/1.0/) applies to the data made available in this article, unless otherwise stated in a credit line to the data. 
women in poor counties, suggesting continued sociodemographic disparities in access to care [1].

Adjuvant endocrine therapy (AET) is recommended for $\mathrm{BCA}$ patients with estrogen receptor (ER) or progesterone receptor (PR) positive BCA. About $60-75 \%$ of invasive BCA cases are ER-positive [4, 6], and $65 \%$ of these cancers are also PR-positive [7]. Several randomized clinical trials of tamoxifen and aromatase inhibitors (AIs) established their positive effects on overall, disease-free, and recurrence-free survival [8-18]. Given this evidence, American Society of Clinical Oncology (ASCO) and National Comprehensive Cancer Network ( $\mathrm{NCCN}$ ) guidelines recommend use of tamoxifen for BCA in premenopausal women and the use of an AI for postmenopausal women, either as primary therapy, as sequential therapy, or in the extended adjuvant setting $[19,20]$.

Previous research has shown that personal, social, and structural factors are associated with guidelineconcordant use of AET among BCA patients [21, 22]. Older age, low socioeconomic status, non-White race/ ethnicity, higher levels of comorbidities and disability, and nonprivate insurance are factors associated with delayed initiation of adjuvant BCA therapies [23-30]. In particular, health insurance coverage is a significant factor associated with initiation of guideline-recommended treatment for BCA. Multiple studies found that higher patient out-of-pocket costs were inversely associated with adherence to AETs, suggesting the importance of comprehensive insurance coverage in ensuring access to therapy along the cancer care continuum [31-33].

To better understand the impact of insurance coverage on initiation of AET and associated socioeconomic disparities among BCA patients, we examine the impacts of the Massachusetts Health Care Insurance Reform Law passed in 2006 (hereafter, Massachusetts health reform), which increased the rate of insurance coverage in the state as well as the scope of covered benefits for many who were already previously insured [34]. The reform mandated that every individual in the state have health insurance if affordable coverage is available to them. To ensure the affordability of insurance plans, the Commonwealth of Massachusetts expanded its Medicaid program (the health insurance program for low-income and disabled individuals), instituted insurance market reforms, and required employers not offering insurance to contribute to the financing of insurance premium subsidies [35]. In addition, the Commonwealth Health Insurance Connector was established to allow individuals without access to employer-sponsored insurance to purchase community-rated insurance directly [36].

This study examines changes in initiation of AET among non-elderly women in low-income areas diagnosed with BCA following health reform in Massachusetts. We hypothesize that changes in the proportion of
BCA patients who initiate AET will be more substantial among women from lower-income areas, who are most likely to be impacted by the reform, than those from higher-income areas in Massachusetts.

\section{Methods}

\section{Data source}

Our primary data source is the Massachusetts Cancer Registry (MCR), which is administered by the Massachusetts Department of Public Health and follows standards set by the North American Association of Central Cancer Registries (NAACCR), the Commission on Cancer $(\mathrm{CoC})$, the National Cancer Institute $(\mathrm{NCI})$, and the Centers for Disease Control and Prevention (CDC) [37]. The MCR collects sociodemographic information of patients (age, sex, race, ethnicity, marital status, and geographic area), cancer diagnosis (date of diagnosis, primary site, stage at diagnosis, and other tumor details) and treatment information from various health care settings within the state. We also used the American Community Survey (ACS), which is administered by the US Census Bureau to collect economic and sociodemographic information from a sample of the US population [38], to estimate median household income at the ZIPcode level in 2006. The Area Health Resources Files (AHRF) were used to control for county-level health care capacity and infrastructure.

\section{Study population}

Out of BCA cases diagnosed during the study period of 2004-2013 in Massachusetts, we eliminated cases among non-female patients; cases in patients under 20 or over 64 years of age, given they were not directly impacted by the insurance reforms; cases for which the patient had another BCA diagnosis within the study period on or before the date of diagnosis of the current case; cases for which diagnosis was established by autopsy or death certificate or where diagnosis date was the same as death date; cases for which the patient had another BCA diagnosed within 365 days; cases that did not receive surgery; cases with ER-negative status; cases with incomplete PR status (data not collected or not documented); cases with stage IV diagnosis; cases with no information on initiation of AET; and cases whose date of endocrine therapy preceded the date of surgery. Figure 1 illustrates how the final study sample of all ER-positive BCA surgical patients ages 20-64 years with complete AET initiation information in Massachusetts from 2004 to 2013 was derived $(n=20,713)$.

\section{Statistical analysis}

We estimated a linear probability regression model to examine differential changes in the likelihood of initiating $\mathrm{AET}$ among BCA patients residing in lower-income 


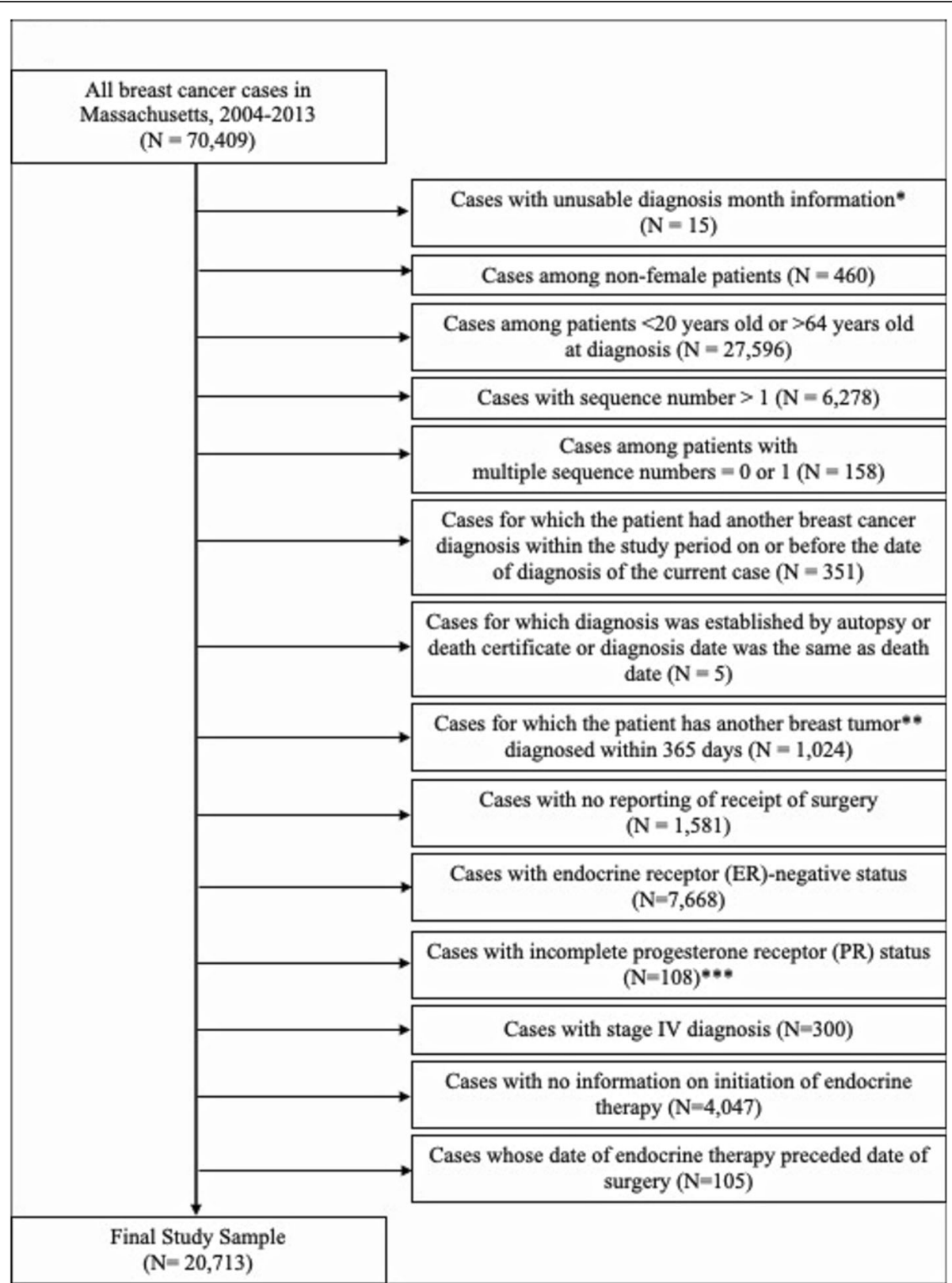

Fig. 1 Study Sample Selection and Exclusions. *We assumed cases with missing diagnosis day but with usable data on month to have occurred on the 15th of the month. ${ }^{* *}$ Exclusion is based on subsequent breast cancer tumors only. ${ }^{* *} \mid$ ncomplete PR status corresponds to the following cases: PR status information was not collected for this case or not documented in patient record

areas compared to those in higher-income areas in Massachusetts. Our model includes a binary variable identifying lower-income ZIP code areas, another binary variable indicating the post-reform period, and an interaction term between these two binary variables to assess population-level differential impacts of the state health reform on initiation of AET among BCA patients living in lower- versus higher-income areas of Massachusetts. The outcome variable is a binary variable indicating whether the patient initiated AET after surgery. ZIP code areas with median household income below the state median value in $2006(\$ 68,293)$, were categorized as low-income areas; this designation was used to capture a population most likely impacted by the reform. The comparison group was BCA patients who lived in ZIP code areas with median household income above the state median income. The pre-reform period includes 2003-2006; the post-reform period includes 2007-2013. We adjusted for patient age, marital status, race/ethnicity, and stage at diagnosis. We controlled for 
secular trends in BCA treatments by adjusting for each calendar year in the model. An individual-specific error term was estimated using Huber-White robust standard errors.

We conducted two additional sets of models to test whether the changes in the initiation of AET were sensitive to definition of low-income areas and study period. The first model defined low-income areas as the lowest tertile ZIP code areas and high-income areas as the highest tertile ZIP code areas in Massachusetts and compared subgroups of patients most likely and least likely to be impacted by the health reform. The second model truncated the post-reform period in 2010 to account for the introduction of generic AIs in 2010 [32]. In addition, we estimated three additional sets of models to test robustness of results to sample inclusions and model covariates: 1) including only patients who were both ER and PR positive, 2) excluding patients whose derived American Joint Committee on Cancer (AJCC) stage was 0 , and 3) adjusting for county-level characteristics including median household income, number of providers (primary care physicians, specialists, and safety net providers) per 1000 population, number of hospital beds per 1000 population, percent unemployed ( $>16$ years old), percent without a high school diploma ( $>25$ years old), percent of White Non-Hispanic/Latino, and percent urban residents [39].

To supplement our main results comparing populationlevel average changes in proportions of $\mathrm{BCA}$ patients residing in low-income areas who initiate AET after surgery to those in high-income areas, we estimated a linear model to assess overall changes in temporal trends in AET initiation. This model includes a time variable that measures the study period by quarter and ranges from 0 (first quarter of 2003) to 39 (fourth quarter of 2013), a binary variable that indicates the pre-reform period as 0 and the post-reform period as 1 which indicates the level change following the state health reform, and an interaction variable between these two variables which indicates the slope change following the state health reform. We adjusted for patient age, marital status, race/ethnicity, stage at diagnosis, and county-level characteristics described above.

\section{Results}

Table 1 presents the characteristics of the sample before and after Massachusetts health reform. About $71 \%$ of BCA patients initiated AET statewide before the reform; after the reform, this proportion increased by 6.2 percentage points. In lower-income ZIP code areas, we observed an increase of 8.8 percentage points in the proportion of BCA patients who initiated AET after surgery; in higher-income ZIP code areas, there was an increase of 4.2 percentage points.
More BCA patients were diagnosed at stage 0 or I in ZIP code areas above state median household income in the pre-reform period; however, this difference was attenuated in the post-reform period. The number of BCA patients who had a mastectomy with reconstruction increased statewide in the post-reform while the number of BCA patients who had breast-conserving surgery (BCS) decreased more in higher-income ZIP code areas. Women residing in high income areas were more likely to be married and less likely to be non-Hispanic White compared to women residing in low-income areas.

Table 2 presents differential changes in the likelihood of initiating AET between BCA patients residing in lowincome versus high-income areas, adjusting for patient characteristics. There was a 5-percentage point increase ( $p$-value $<0.001)$ in the likelihood of initiating AET following the Massachusetts reform in low-income ZIP codes, relative to the increase in the higher income ZIP codes. This effect was more pronounced among younger BCA patients ages 20-49 years, for whom we observed a 7.1-percentage point $(p$-value $=0.001)$ relative increase in the likelihood of initiating AET relative to the comparison group.

When we shortened the post-reform period to isolate changes after health insurance expansions prior to the introduction of generic AIs (Table 3, column 1), we observed a significant relative increase in the likelihood of initiating AET among BCA patients aged 20-64 years. However, the differential effect of Massachusetts health reform on the likelihood of initiating AET among older women residing in low-income areas was no longer significant when the post-reform period was restricted to 2007-2010. Using tertiles to define the low- and highincome areas in Massachusetts (Table 3, column 2), the estimates were robust to the alternative specification of income categories. We consistently observed a significant increase in the likelihood of initiating AET among $\mathrm{BCA}$ patients residing in lower-income areas in MA when we restricted the study population as ER- and PRpositive BCA patients (Table 4, Column 1), excluded patients diagnosed with in situ disease (Table 4, Column 2 ), and adjusted for county-level demographic and health care capacity variables (Table 4, Column 3).

To assess pre-trends of the outcome, we estimated event study regressions for all models and considered the joint F-test on interactions between income category and year in the pre-period to test the pre-period significance level (Additional file 1: Appendix Table 1). We observed that the pre-trends of the outcome were not significantly different between lower-income areas and higher-income areas in MA.

In addition, Fig. 2 presents temporal trends in the adjusted predicted percentage of BCA patients initiating AET in Massachusetts quarterly from 2004 to 
Table 1 Characteristics of the study population before and after Massachusetts health reform

\begin{tabular}{|c|c|c|c|c|c|c|}
\hline & \multicolumn{2}{|c|}{$\begin{array}{l}\text { All ZIP code areas in } \\
\text { Massachusetts }\end{array}$} & \multicolumn{2}{|c|}{$\begin{array}{l}\text { ZIP code areas below state median } \\
\text { household income }^{\text {a }}\end{array}$} & \multicolumn{2}{|c|}{$\begin{array}{l}\text { ZIP code areas above state median } \\
\text { household income }^{a}\end{array}$} \\
\hline & Pre-reform & Post-reform & Pre-reform & Post-reform & Pre-reform & Post-reform \\
\hline $\mathrm{N}$ & 6539 & 14,174 & 2839 & 6159 & 3656 & 7897 \\
\hline Adjuvant Endocrine Therapy & 70.99 & 77.23 & 67.35 & 76.15 & 73.85 & 78.00 \\
\hline \multicolumn{7}{|l|}{ Stage at diagnosis ${ }^{\mathrm{b}}$} \\
\hline 0 & 24.64 & 24.90 & 23.14 & 25.09 & 25.68 & 24.78 \\
\hline । & 44.49 & 45.81 & 44.03 & 44.94 & 45.08 & 46.41 \\
\hline$\|$ & 23.61 & 23.07 & 24.48 & 23.28 & 22.01 & 22.95 \\
\hline III & 7.26 & 6.22 & 8.35 & 6.69 & 6.43 & 5.86 \\
\hline \multicolumn{7}{|l|}{ Type of Surgery } \\
\hline BCS & 73.93 & 71.89 & 73.09 & 72.74 & 74.07 & 71.15 \\
\hline Mastectomy with RC & 9.93 & 17.13 & 8.45 & 14.97 & 11.18 & 18.87 \\
\hline Mastectomy without RC & 16.15 & 10.98 & 17.86 & 12.29 & 14.85 & 9.98 \\
\hline \multicolumn{7}{|l|}{ Hormone Receptor Status } \\
\hline Both ER and PR Positive & 84.98 & 86.84 & 85.07 & 86.59 & 84.96 & 87.01 \\
\hline ER Positive only & 15.02 & 13.16 & 14.93 & 13.41 & 15.04 & 12.99 \\
\hline \multicolumn{7}{|l|}{ Demographic Information } \\
\hline Age $<40$ & 6.35 & 6.03 & 7.20 & 6.67 & 5.58 & 5.57 \\
\hline Age 40-49 & 34.52 & 31.66 & 31.77 & 29.49 & 36.65 & 33.43 \\
\hline Age $50-54$ & 20.20 & 20.69 & 20.36 & 19.58 & 20.13 & 21.63 \\
\hline Age 55-59 & 19.97 & 19.92 & 20.43 & 21.58 & 19.64 & 18.59 \\
\hline Age 60-64 & 18.96 & 21.69 & 20.15 & 22.68 & 18.00 & 20.78 \\
\hline Married & 64.73 & 64.05 & 56.43 & 55.76 & 71.20 & 70.63 \\
\hline Non-Hispanic White & 89.88 & 86.91 & 84.04 & 79.12 & 94.42 & 92.91 \\
\hline Non-Hispanic Black & 3.38 & 4.54 & 6.23 & 8.39 & 1.18 & 1.56 \\
\hline Non-Hispanic Other Race & 2.95 & 4.30 & 2.71 & 4.51 & 3.12 & 4.18 \\
\hline Hispanic & 3.79 & 4.25 & 7.01 & 7.97 & 1.29 & 1.3 \\
\hline
\end{tabular}

Pre-reform period is January 2003 - June 2007; Post-reform period is July 2007 - December 2013

AET Adjuvant Endocrine Therapy, AJCC American Joint Committee on Cancer, BCS Breast Conserving Surgery, RC Reconstruction, ER Estrogen Receptor, PR Progesterone Receptor

aThe estimated median household income in MA was $\$ 68,293.37$ in 2006

${ }^{\mathrm{b}}$ Measured by derived AJCC Stage Group

2013. Considering the adjusted predicted percentage of BCA patients initiating AET in the pre-reform period, a higher percentage of $\mathrm{BCA}$ patients residing in high income areas in MA initiated AET after surgery than $\mathrm{BCA}$ patients residing in low income areas on average. However, the percentage of BCA patients residing in low income ZIP codes in MA initiating $\mathrm{AET}$ and that of BCA patients residing in high income ZIP codes in MA initiating AET converge at quarter 20, about 2 years after the state health reform. From quarter 20 till the end of the study period, we observe a higher proportion of BCA patients residing in low income ZIP codes in MA initiating AET after surgery than BCA patients residing in high income ZIP codes in MA.

\section{Discussion}

In this study, we examined the differential impact of Massachusetts health reform on the initiation of AET in lower-income ZIP codes, where residents were most likely to be impacted by the reform, and higherincome ZIP codes in Massachusetts. The expansion of health insurance resulted in positive relative changes in the proportion of $\mathrm{BCA}$ patients in lower-income areas of the state who initiate AET. The most pronounced effects of Massachusetts health reform were in women ages $20-49$ years. The relative percentagepoint change between the pre-and post-reform periods among the younger sample of women was twice as large as that of older women (7.1-percentage points vs. 3.6-percentage points). 
Table 2 Changes in likelihood of initiating AET after state health reform in low-income areas in Massachusetts

\begin{tabular}{|c|c|}
\hline \multirow[t]{2}{*}{ Breast cancer patients aged 20-64 years } & $0.050^{* * *}$ \\
\hline & {$[0.024,0.075]$} \\
\hline N & 20,551 \\
\hline \multirow[t]{2}{*}{ Breast cancer patients aged 20-49 years } & $0.071^{* * *}$ \\
\hline & {$[0.029,0.113]$} \\
\hline $\mathrm{N}$ & 7960 \\
\hline \multirow[t]{2}{*}{ Breast cancer patients aged $50-64$ years } & $0.036^{* *}$ \\
\hline & {$[0.004,0.068]$} \\
\hline $\mathrm{N}$ & 12,591 \\
\hline \multicolumn{2}{|c|}{$\begin{array}{l}\text { This table presents estimates from multivariable difference-in-differences } \\
\text { regressions comparing women living in low-income ZIP code areas to those in } \\
\text { high-income ZIP codes of Massachusetts before and after state health reform. } \\
\text { All models control for age at diagnosis, marital status, race/ethnicity, stage at } \\
\text { diagnosis, and type of surgery } \\
\text { AET Adjuvant Endocrine Therapy } \\
* * * p \text {-value }<0.01{ }^{* *} p \text {-value }<0.05\end{array}$} \\
\hline
\end{tabular}

Massachusetts health reform increased access to medical care, improved financial support for safety-net hospitals, and provided more expansive prescription drug coverage. In particular, younger patients were more likely to gain coverage under state health reform. A 2004 Massachusetts Health Insurance Survey found that over 90\% of newly enrolled Medicaid enrollees after Massachusetts health reform were previously unenrolled [35]. Previous studies have demonstrated that higher out of pocket prescription drug costs are associated with lower initiation and higher discontinuation of medications and treatments [27, 31, 32, 40-44]. Our study further supports these findings, estimating about a 5-percentage point relative increase in the likelihood of BCA patients aged 20-64 years in low-income areas initiating AET after reform relative to BCA patients in the same age group living in high-income areas. Given that AET is recommended for extended periods, even small monthly costs may add up to a substantial financial burden over time $[45,46]$.

Socioeconomic disparities in mortality among BCA patients have persisted despite increases in overall survival rates over recent decades. According to a recent report by the American Cancer Society, the mortality rate among BCA patients in poor counties was about 1.16 times higher than that in affluent counties. The observed relative increases in likelihood of initiating AET among younger women in lower-income areas who were more likely to have been without health insurance prior to the reform implies that Massachusetts health reform reduced disparities in receipt of adjuvant therapy and has important implications for health outcomes among BCA patients. This study examines initiation of AET, though AET adherence is also critical for reducing breast cancer recurrence rates, thus future studies estimating the effects of state and federal health reforms on adherence to AET would provide additional insight regarding the impact of health insurance policy changes on health outcomes.

This study has limitations. First, the limited prereform period might not have captured other secular trends that contributed to the increased likelihood of initiation of AET among BCA patients. Second, we did not have comparable data available from other states, limiting the geographic generalizability of our findings and the ability to include a control group that was not impacted by the reform in any way. However, this study compared ZIP codes where the median household income was below the state median household income to

Table 3 Changes in likelihood of initiating AET after state health reform in low-income areas in Massachusetts by age group

\begin{tabular}{|c|c|c|}
\hline & $(1)$ & (2) \\
\hline & Post-reform: 2007-2010 & Low-income areas: lowest tertile ZIP code areas \\
\hline \multirow[t]{2}{*}{ Breast cancer patients aged $20-64$ years } & $0.035^{* * *}$ & $0.068^{* * *}$ \\
\hline & {$[0.006,0.065]$} & {$[0.038,0.099]$} \\
\hline$N$ & 13,906 & 14,185 \\
\hline \multirow[t]{2}{*}{ Breast cancer patients aged $20-49$ years } & $0.061^{* * *}$ & $0.072^{* * *}$ \\
\hline & {$[0.013,0.109]$} & {$[0.022,0.122]$} \\
\hline N & 5588 & 5542 \\
\hline \multirow[t]{2}{*}{ Breast cancer patients aged $50-64$ years } & 0.018 & $0.064^{* * *}$ \\
\hline & {$[-0.019,0.055]$} & {$[0.025,0.103]$} \\
\hline $\mathrm{N}$ & 8318 & 8643 \\
\hline
\end{tabular}

Model (1) re-defines the post-reform period to be 2007-2010. Model (2) re-defines the low-income areas to be the lowest tertile ZIP code areas and the highincome areas to be the highest tertile ZIP code areas in Massachusetts. Both models are based on the main multivariable difference-in-differences regressions in Table 2. All models control for age at diagnosis, marital status, race/ethnicity, stage at diagnosis, and type of surgery AET Adjuvant Endocrine Therapy

${ }^{* * *} p$-value $<0.01{ }^{* *} p$-value $<0.05$ 
Table 4 Robustness checks on changes in initiation of AET after state health reform in low-income areas vs. high-income area

\begin{tabular}{|c|c|c|c|}
\hline & (1) & $(2)$ & (3) \\
\hline & $\begin{array}{l}\text { Breast cancer patients who } \\
\text { are both ER and PR positive }\end{array}$ & $\begin{array}{l}\text { Excluding patients with in } \\
\text { situ disease at diagnosis }{ }^{1}\end{array}$ & Adjusting for county-level controls ${ }^{2}$ \\
\hline \multirow[t]{2}{*}{ Breast cancer patients aged $20-64$ years } & $0.038^{* * *}$ & $0.049 * * *$ & $0.051^{* * *}$ \\
\hline & {$[0.106,0.065]$} & {$[0.021,0.076]$} & {$[0.025,0.077]$} \\
\hline $\mathrm{N}$ & 17,725 & 15,543 & 20,551 \\
\hline \multirow[t]{2}{*}{ Breast cancer patients aged $20-49$ years } & $0.056^{* *}$ & $0.087^{* * *}$ & $0.068^{* * *}$ \\
\hline & {$[0.012,0.100]$} & {$[0.040,0.133]$} & {$[0.026,0.110]$} \\
\hline $\mathrm{N}$ & 7110 & 5801 & 7960 \\
\hline \multirow[t]{2}{*}{ Breast cancer patients aged 50-64 years } & 0.025 & 0.026 & $0.040^{* *}$ \\
\hline & {$[-0.009,0.060]$} & {$[-0.009,0.061]$} & {$[0.007,0.072]$} \\
\hline $\mathrm{N}$ & 10,615 & 9652 & 12,591 \\
\hline
\end{tabular}

These robustness checks were conducted in the main multivariable difference-in-differences regressions in Table 2, which controls for age at diagnosis, marital status, race/ethnicity, stage at diagnosis, and type of surgery

AET Adjuvant Endocrine Therapy, ER Estrogen Receptor, PR Progesterone receptor

${ }^{* * *} p$-value $<0.01{ }^{* *} p$-value $<0.05$

${ }^{\mathrm{a}}$ Derived American Joint Committee on Cancer (AJCC) stage $=0$

${ }^{\mathrm{b}}$ Median household income, percent unemployed, percent with less than a high school education, percent non-Hispanic white, percent urban; and primary care physicians, specialist physicians, safety net provider, and hospital beds all specified as rate per 1000 population

those where median household income was above the state median household income in an effort to compare a population most likely to be impacted by the reform to a comparable group. Given that those in higher-income areas also stood to benefit from certain provisions of the health reform, our estimates of the differential impact on patients from lower- versus higher-income areas may represent an underestimate of the full impact of reform. Fourth, due to the nature of cancer registry data, there was no relevant clinical information, including

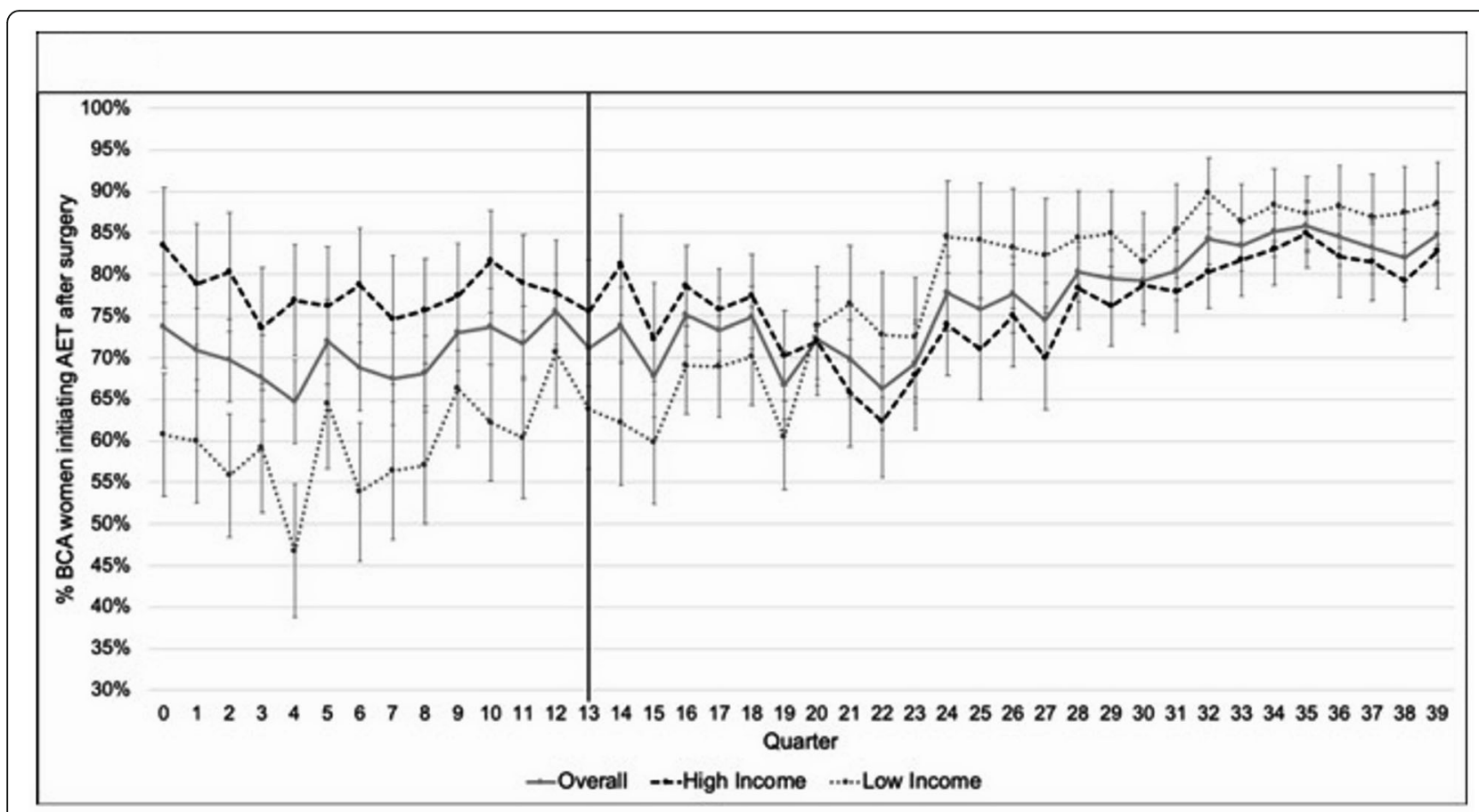

Fig. 2 Adjusted predicted \% BCA patients initiating AET in Massachusetts by quarter from 2003 to 2014. The model adjusted for age, race/ethnicity, marital status, stage at diagnosis, ER status, type of surgery received, low-, intermediate-, and high income areas, county-level characteristics including median household income, number of providers (primary care physicians, specialists, and safety net providers) per 1000 population, number of hospital beds per 1000 population, percent unemployed (> 16years old), percent without a high school diploma (> 25 years old), percent of White Non-Hispanic/Latino, and percent urban residents. BCA: Breast Cancer; AET: Adjuvant Endocrine Therapy; ER: Estrogen Receptor 
menopausal status and comorbidities, and other potential socioeconomic information including patient's education and income that can impact initiation of AET. However, regarding patient's menopausal status, we adjusted for BCA patients' age as a proxy. Fifth, local area (such as ZIP code-level) health care capacity characteristics, such as the number of providers, were not adjusted for in the model. Estimates from models that adjusted for county-level health care capacity characteristics were strikingly similar to estimates from our main model.

\section{Conclusions}

Disparities in BCA outcomes by socioeconomic factors, such as poor insurance coverage and lack of financial resources, persist. Given that about two-thirds of earlystage BCA cases are hormone-responsive, our findings indicate that expansion of health insurance coverage increases the number of eligible patients initiating AET and insurance coverage expansion may be an important policy tool for reducing income disparities in BCA outcomes, including survival. Timely initiation of and adherence to AET will result in better prognosis, which will prevent recurrence rates and improve survival of patients. This evidence from Massachusetts health reform underscores the significance of continued efforts to expand coverage across the US and emphasizes the importance of evaluating the effect of other relevant health insurance policies, such as the Affordable Care Act (ACA), on the uptake of adjuvant treatment among cancer patients.

\begin{abstract}
Abbreviations
ACA: Affordable Care Act; ACS: American Community Survey; AET: Adjuvant Endocrine Therapy; AHRF: Area Health Resources Files; Al: Aromatase Inhibitor; AJCC: American Joint Committee on Cancer; ASCO: American Society of Clinical Oncology; BCA: Breast Cancer; CDC: The Centers for Disease Control and Prevention; CoC: The Commission on Cancer; ER: Estrogen Receptor; MA: Massachusetts; MCR: Massachusetts Cancer Registry; NAACCR: North American Association of Central Cancer Registries; NCCN: National Comprehensive Cancer Network; PR: Progesterone Receptor
\end{abstract}

\section{Supplementary Information}

The online version contains supplementary material available at https://doi. org/10.1186/s12885-021-08149-0.

Additional file 1: Table S1. Event study estimates to test parallel trends in the pre-reform period for all models. Table S2. Comparing various definitions of low-income areas to estimate changes in likelihood of initiating AET after state health reform in low-income areas in Massachusetts.

\section{Acknowledgments}

The authors thank the Massachusetts Department of Public Health for assistance accessing data.

\section{Authors' contributions}

KYE cleaned the Massachusetts Cancer Registry data, performed statistical analysis for the study and interpreted the results, and wrote and edited the manuscript for submission. GJL provided clinical insights in interpreting the results and edited the manuscript. JL assisted in cleaning the data for analysis. BD provided his statistical expertise in data analysis and interpretation of the results. CB helped with interpreting the results and editing the manuscript for submission. LMS designed the study, acquired the data, oversaw the entire data analysis process, and wrote and edited he manuscript for submission. The author(s) read and approved the final manuscript.

\section{Funding}

This research was supported by the American Cancer Society (Research Scholar Grant RSG-16-017-01-CPHPS) and National Cancer Institute Cancer Center Support Grant P30 CA047904.

Availability of data and materials

The datasets analyzed during the current study are not publicly available as the Massachusetts Department of Public Health accessed restricted data from Massachusetts Cancer Registry under a Data Use Agreement.

\section{Declarations}

Ethics approval and consent to participate

All methods were carried out in accordance with relevant guidelines and regulations.

IRB approval and informed consent were not applicable as this study used anonymized sociodemographic and clinical information of confirmed cancer cases among cancer patients collected by the Commonwealth of Massachusetts and the authors accessed this restricted cancer registry data and received for approval of the publication of the data under a Data Use Agreement with the Massachusetts Department of Public Health.

Consent for publication

Not applicable.

\section{Competing interests}

The authors declare that they have no competing interests.

\section{Author details}

${ }^{1}$ Department of Health Policy and Management, University of Pittsburgh, 130 De Soto St, A663, Pittsburgh, PA 15261, USA. ²Divisions of Hematology-Oncology and Geriatric Medicine, Department of Medicine, University of Pittsburgh, Pittsburgh, USA. ${ }^{3}$ Department of Health Behavior and Policy, Virginia Commonwealth University, Richmond, USA. ${ }^{4}$ University of Colorado Comprehensive Cancer Center, Aurora, USA.

Received: 12 January 2021 Accepted: 30 March 2021

Published online: 01 May 2021

\section{References}

1. Siegel RL, Miller KD, Jemal A. Cancer statistics, 2019. CA Cancer J Clin. 2019; 69(1):7-34. https://doi.org/10.3322/caac.21551.

2. The Office of Data Management and Outcomes Assessment. Cancer Incidence and Mortality in Massachusetts 2008-2012: Statewide Report. https://www.mass.gov/files/documents/2016/12/ti/registry-statewide-report08-12.pdf. Accessed 23 Oct 2019

3. The Office of Data Management and Outcomes Assessment. Cancer Incidence and Mortality in Massachusetts 2011-2015: Statewide Report. https://www.mass.gov/files/documents/2018/07/27/Cancer-incidence-andmortality-statewide-2011-2015.pdf. Accessed 23 Oct 2019.

4. American Cancer Society. Breast Cancer Facts \& Figures 2017-2018. https:// www.cancer.org/content/dam/cancer-org/research/cancer-facts-andsta tistics/breast-cancer-facts-and-figures/breast-cancer-facts-and-figures-2017-2 018.pdf. Accessed 23 Oct 2019.

5. Kohler BA, Sherman RL, Howlader N, Jemal A, Ryerson AB, Henry KA, et al. Annual Report to the Nation on the Status of Cancer, 1975-2011, Featuring Incidence of Breast Cancer Subtypes by Race/Ethnicity, Poverty, and State. J Natl Cancer Inst. 2015;107(6):djv048.

6. Howlader N, Altekruse SF, Li Cl, Chen WW, Clarke CA, Ries LA, Cronin KA. US incidence of breast cancer subtypes defined by joint hormone receptor and HER2 status. J Natl Cancer Inst. 2014;106(5):dju055.

7. The National Cancer Institute. Hormone Therapy for Breast Cancer https:// www.cancer.gov/types/breast/breast-hormone-therapy-fact-sheet. Accessed 8 Aug 2019. 
8. Burstein HJ, Temin S, Anderson H, Buchholz TA, Davidson NE, Gelmon KE, et al. Adjuvant endocrine therapy for women with hormone receptorpositive breast cancer: american society of clinical oncology clinical practice guideline focused update. J Clin Oncol. 2014;32(21):2255-69. https://doi. org/10.1200/JCO.2013.54.2258.

9. Jankowitz RC, Davidson NE. Adjuvant endocrine therapy for breast cancer: how long is long enough? Oncology (Williston Park, NY). 2013;27(12):1210-6 1224.

10. Controlled trial of tamoxifen as a single adjuvant agent in the management of early breast cancer. 'Nolvadex' Adjuvant Trial Organisation. Brit J Cancer 1988, 57(6):608-611.

11. Fisher B, Costantino J, Redmond C, Poisson R, Bowman D, Couture J, et al. A randomized clinical trial evaluating tamoxifen in the treatment of patients with node-negative breast cancer who have estrogen-receptor-positive tumors. N Engl J Med. 1989;320(8):479-84. https://doi.org/10.1056/NEJM1 98902233200802.

12. Fisher B, Dignam J, Bryant J, DeCillis A, Wickerham DL, Wolmark N, et al. Five versus more than five years of tamoxifen therapy for breast cancer patients with negative lymph nodes and estrogen receptor-positive tumors. J Natl Cancer Inst. 1996;88(21):1529-42. https://doi.org/10.1093/jnci/88.21.1529.

13. Early Breast Cancer Trialists' Collaborative Group. Effects of chemotherapy and hormonal therapy for early breast cancer on recurrence and 15-year survival: an overview of the randomised trials. Lancet. 2005;365(9472):1687-717.

14. Early Breast Cancer Trialists' Collaborative Group. Relevance of breast cancer hormone receptors and other factors to the efficacy of adjuvant tamoxifen: patient-level meta-analysis of randomised trials. Lancet. 2011;378(9793):77184. https://doi.org/10.1016/S0140-6736(11)60993-8.

15. Howell A, Cuzick J, Baum M, Buzdar A, Dowsett M, Forbes JF, et al. Results of the ATAC (Arimidex, Tamoxifen, alone or in combination) trial after completion of 5 years' adjuvant treatment for breast cancer. Lancet. 2005; 365(9453):60-2. https://doi.org/10.1016/S0140-6736(04)17666-6.

16. Regan MM, Price KN, Giobbie-Hurder A, Thurlimann B, Gelber RD. Interpreting breast international group (BIG) 1-98: a randomized, doubleblind, phase III trial comparing letrozole and tamoxifen as adjuvant endocrine therapy for postmenopausal women with hormone receptorpositive, early breast cancer. Breast Cancer Res. 2011;13(3):209. https://doi. org/10.1186/bcr2837

17. Early Breast Cancer Trialists' Collaborative Group. Aromatase inhibitors versus tamoxifen in early breast cancer: patient-level meta-analysis of the randomised trials. Lancet. 2015;386(10001):1341-52

18. Pan H, Gray R, Braybrooke J, Davies C, Taylor C, McGale P, et al. 20-year risks of breast-Cancer recurrence after stopping endocrine therapy at 5 years. N Engl J Med. 2017;377(19):1836-46. https://doi.org/10.1056/NEJMoa1701830.

19. Burstein HJ, Prestrud AA, Seidenfeld J, Anderson H, Buchholz TA, Davidson $\mathrm{NE}$, et al. American Society of Clinical Oncology clinical practice guideline: update on adjuvant endocrine therapy for women with hormone receptorpositive breast cancer. J Clin Oncol. 2010;28(23):3784-96. https://doi.org/1 0.1200/JCO.2009.26.3756.

20. National Comprehensive Cancer Network. NCCN clinical practice guidelines in oncology (NCCN guidelines) (version 3.2019). https://www.nccn.org/ professionals/physician_gls/pdf/breast.pdf. Accessed 2 Nov 2019.

21. Griggs JJ. Role of nonclinical factors in the receipt of high-quality systemic adjuvant breast cancer treatment. J Clin Oncol. 2012;30(2):121-4. https://doi. org/10.1200/JCO.2011.39.4270.

22. Lambert LK, Balneaves LG, Howard AF, Chia SK, Gotay CC. Understanding adjuvant endocrine therapy persistence in breast Cancer survivors. BMC Cancer. 2018;18(1):732. https://doi.org/10.1186/s12885-01 8-4644-7.

23. Wu XC, Lund MJ, Kimmick GG, Richardson LC, Sabatino SA, Chen WW, et al Influence of race, insurance, socioeconomic status, and hospital type on receipt of guideline-concordant adjuvant systemic therapy for locoregional breast cancers. J Clin Oncol. 2012;30(2):142-50. https://doi.org/10.1200/JCO.2 011.36.8399

24. Freedman RA, Virgo KS, He Y, Pavluck AL, Winer EP, Ward EM, et al. The association of race/ethnicity, insurance status, and socioeconomic factors with breast cancer care. Cancer. 2011;117(1):180-9. https://doi.org/10.1002/ cncr.25542.

25. Yu XQ. Socioeconomic disparities in breast cancer survival: relation to stage at diagnosis, treatment and race. BMC Cancer. 2009;9(1):364. https://doi. org/10.1186/1471-2407-9-364.

26. Kimmick G, Anderson R, Camacho F, Bhosle M, Hwang W, Balkrishnan R. Adjuvant hormonal therapy use among insured, low-income women with breast cancer. J Clin Oncol. 2009;27(21):3445-51. https://doi.org/10.1200/ JCO.2008.19.2419.

27. Hershman DL, Kushi LH, Shao T, Buono D, Kershenbaum A, Tsai WY, et al. Early discontinuation and nonadherence to adjuvant hormonal therapy in a cohort of 8,769 early-stage breast cancer patients. J Clin Oncol. 2010;28(27): 4120-8. https://doi.org/10.1200/JCO.2009.25.9655.

28. Yung RL, Hassett MJ, Chen K, Gesten FC, Roohan PJ, Boscoe FP, et al. Initiation of adjuvant hormone therapy by Medicaid insured women with nonmetastatic breast cancer. J Natl Cancer Inst. 2012;104(14):1102-5. https:// doi.org/10.1093/jnci/djs273.

29. Sheppard VB, de Mendoza AH, He J, Jennings Y, Edmonds MC, Oppong BA, et al. Initiation of Adjuvant Endocrine Therapy in Black and White Women With Breast Cancer. Clin Breast Cancer. 2018;18(5):337-46 e331.

30. Chavez-MacGregor M, Clarke CA, Lichtensztajn DY, Giordano SH. Delayed initiation of adjuvant chemotherapy among patients with breast Cancer. JAMA Oncol. 2016;2(3):322-9. https://doi.org/10.1001/jamaoncol.2015.3856.

31. Bradley CJ, Dahman B, Jagsi R, Katz S, Hawley S. Prescription drug coverage: implications for hormonal therapy adherence in women diagnosed with breast cancer. Breast Cancer Res Treat. 2015;154(2):417-22. https://doi.org/1 0.1007/s10549-015-3630-x.

32. Hershman DL, Tsui J, Meyer J, Glied S, Hillyer GC, Wright JD, et al. The change from brand-name to generic aromatase inhibitors and hormone therapy adherence for early-stage breast cancer. J Natl Cancer Inst. 2014;106(11):dju319.

33. Hershman DL, Tsui J, Wright JD, Coromilas EJ, Tsai WY, Neugut Al. Household net worth, racial disparities, and hormonal therapy adherence among women with early-stage breast Cancer. J Clin Oncol. 2015;33(9): 1053-9. https://doi.org/10.1200/JCO.2014.58.3062.

34. The Commonwealth of Massachusetts. Health care reform for individuals. https://www.mass.gov/info-details/health-care-reform-for-individuals. Accessed 11 Oct 2019

35. Doonan MT, Tull KR. Health care reform in Massachusetts: implementation of coverage expansions and a health insurance mandate. Milbank Q. 2010; 88(1):54-80. https://doi.org/10.1111/j.1468-0009.2010.00589.x.

36. McDonough JE, Rosman B, Phelps F, Shannon M. The Third Wave Of Massachusetts Health Care Access Reform. Health Aff. 2006;25(Supplement 1):W420-31

37. The Commonwealth of Massachusetts. About the Massachusetts Cancer Registry (MCR). https://www.mass.gov/service-details/about-the-massa chusetts-cancer-registry-mcr. Accessed 30 July 2019.

38. The United States Census Bureau. American Community Survey. https:// www.census.gov/programs-surveys/acs/about.html. Accessed 8 Aug 2019.

39. Health Resources \& Services Administration. Area Health Resources Files. https://data.hrsa.gov/topics/health-workforce/ahrf. Accessed 8 Aug 2019.

40. Murphy CC, Tiro JA, Jean GW, Balasubramian BA, Alvarez CA. High Initiation of Adjuvant Hormonal Therapy Among Uninsured Stages I-III Breast Cancer Patients Treated in a Safety-Net Healthcare System. J Women's Health (2002). 2017;26(6):655-61.

41. Carrera PM, Kantarjian HM, Blinder VS. The financial burden and distress of patients with cancer: understanding and stepping-up action on the financial toxicity of cancer treatment. CA Cancer J Clin. 2018;68(2):153-65. https://doi.org/10.3322/caac.21443.

42. Neugut Al, Subar M, Wilde ET, Stratton S, Brouse CH, Hillyer GC, et al. Association between prescription co-payment amount and compliance with adjuvant hormonal therapy in women with early-stage breast cancer. J Clin Oncol. 2011;29(18):2534-42. https://doi.org/10.1200/JCO.2010.33.3179.

43. Eaddy MT, Cook CL, O'Day K, Burch SP, Cantrell CR. How patient cost-sharing trends affect adherence and outcomes: a literature review. P T. 2012;37(1):45-55.

44. Ku L, Deschamps E, Hilman J. The effects of copayments on the use of medical services and prescription drugs in Utah's Medicaid program https:// www.cbpp.org/sites/default/files/atoms/files/11-2-04health.pdf. Accessed.

45. Goldman DP, Joyce GF, Zheng Y. Prescription drug cost sharing: associations with medication and medical utilization and spending and health. JAMA. 2007;298(1):61-9. https://doi.org/10.1001/jama.298.1.61.

46. Li P, Wong Y-N, Jahnke J, Pettit AR, Doshi JA. Association of high cost sharing and targeted therapy initiation among elderly Medicare patients with metastatic renal cell carcinoma. Cancer Med. 2018;7(1):75-86. https:// doi.org/10.1002/cam4.1262.

\section{Publisher's Note}

Springer Nature remains neutral with regard to jurisdictional claims in published maps and institutional affiliations. 